Article 174

Received: June 2, 2020

Accepted: October 30, 2020
Journal of Electrical Engineering and Information Technologies, Vol. 5, No. 2, pp. 85-92 (2020)

In print: ISSN $2545-4250$

On line: ISSN 2545-4269

UDC: 534.322.3.015:57.08]:519.226

Original scientific paper

\title{
TOWARDS A PROTOCOL FOR ADAPTIVE DYNAMICAL BAYESIAN INFERENCE: CASE OF LIMIT-CYCLE OSCILLATORS
}

\author{
Duško Lukarski ${ }^{1,2}$, Hristina Spasevska ${ }^{3}$, Tomislav Stankovski ${ }^{4}$ \\ ${ }^{1}$ Faculty of Medicine, "Ss. Cyril and Methodius" University in Skopje, North Macedonia \\ ${ }^{2}$ University Clinic for Radiotherapy and Oncology, "Ss. Cyril and Methodius University" in Skopje, \\ North Macedonia \\ ${ }^{3}$ Faculty of Electrical Engineering and Information Technologies, \\ "Ss. Cyril and Methodius: University in Skopje, North Macedonia \\ ${ }^{4}$ Department of Physics, Lancaster University, Lancaster, United Kingdom \\ dushko.lukarski@medf.ukim.edu.mk
}

\begin{abstract}
A b s t r a c t: Several methods exist that allow the study of the interactions between dynamic systems in nature. Among them is the method of dynamic Bayesian inference, which allows reconstruction of a model that describes the interactions between different dynamical systems, based on the measured time series originating from these systems. Based on an investigation of a known system of two coupled phase oscillators, an algorithm for improving this method has been proposed, by adaptively determining two parameters that were previously arbitrarily selected - the time window and the propagation parameter. This paper presents the results of the evaluation of the introduced algorithm on a second system of coupled oscillators - limit-cycle Poincaré oscillators in the presence of noise. The performed analysis confirmed the relevance of the proposed algorithm for improved model inference, which allows for a deeper understanding of the interactions described by the coupling functions of the dynamical systems.
\end{abstract}

Key words: adaptive dynamical Bayesian inference; coupled oscillators; time window determination

\section{КОН ПРОТОКОЛ ЗА АДАПТИВНА ДИНАМИЧКА БАЕСОВА ИНФЕРЕНЦИЈА: СЛУЧАЈ НА ОСЦИЛАТОРИ НА ГРАНИЧЕН ЦИКЛУС}

А п с т р а к т: Постојат неколку методи кои овозможуваат проучување на заемното дејство на динамичките системи во природата. Меѓу нив е и методот на динамичка Баесова инференција, кој овозможува реконструкција на модел кој гі опишува заемното дејство на различни динамички системи, засновано врз измерени временски серии кои потекнуваат од овие системи. Врз основа на истражување на познат систем од два спрегнати фазни осцилатори е предложен алгоритам за унапредување на овој метод, преку адаптивно одредување на два параметра кои претходно беа произволно избирани - временскиот прозорец и параметарот на пренесување. Во овој труд се презентирани резултатите од евалуацијата на воведениот алгоритам на втор систем спрегнати осцилатори - осцилатори на граничен циклус на Поанкаре во присуство на шум. Спроведените анализи ја потврдуваат релевантноста на предложениот алгоритам за подобрена инференција на моделот, која овозможува подлабоко осознавање на заемното дејство на динамичките системи опишани преку функциите на спрега.

Клучни зборови: адаптивна динамичка Баесова инференција; спрегнати осцилатори; одредување на временски прозорец

\section{INTRODUCTION}

Several oscillatory systems are part of the human body: cardiac function is periodic, respiration is an oscillatory process, brain waves are oscillatory in nature, and so on. Some of these systems have been found to interact with each other, and this interaction has a strong influence on their behavior. The study of the interactions of these oscillatory systems can lead to new ways of describing the physiological states of the healthy organism or determining various pathological conditions $[1-6]$. One of the challenges in studying the oscillatory 
systems of the human body is their time variability. The classical approach in the study of these interactions consists in dismissing this time variability, but such an oversimplification may lead to overlooking key features that actually determine the nature of the phenomenon. Therefore, it is necessary to take into account the dynamics of the interactions of biological systems.

Several methods have been proposed for investigation of the influence one dynamical system exerts on another [7 - 14] and a great deal of them are based on investigations of the phase dynamics of the systems $[1,8,15,16]$. The method that is of interest for this resarch is the dynamical Bayesian inference $[8,16]$ which is used for inference of time varying phase dynamics in the presence of noise. In this method, by investigating time series of oscillator phases obtained by measurements and their processing, a model that describes the system is inferred and then analyzed. From the analysis of the inferred coupling functions, information regarding the interactions of the systems is obtained [17 - 19].

When analyzing the data obtained from the measurements of the dynamic system, one of the general issues is how to determine the length of the time window. Usually, the analyses are performmed in a manner that the time series of the measurement is considered a sequence of blocks of data and the duration of each block is determined by the time window. The time window should be long enough to include enough data for appropriate inference and at the same time, short enough to provide the best possible time resolution to describe the variability of the parameters. In addition, the method of dynamical Bayesian inference uses part of the informations inferred in the previous block of data to make the inference of the current block. How much of the information is propagated from the previous to the next block of inference is determined by the so-called propagation parameter of the covariance matrix. In [20] we proposed a method for determining these two parameters within the dynamical Bayesian inference. In this paper we give further details on testing this method on a system of coupled limit cycle oscillators.

\section{THEORETICAL BACKGROUND}

The dynamical Bayesian inference method [8, 16] is applied to a stochastic differential model where the deterministic part is time varying. We consider two weakly interacting coupled oscillatory systems in presence of noise. In case of weak coupling, the system can be described using the phase approximation approach $[15,21]$. In this approach the oscillator's state is described by a single phase variable which increases monotonically with time. For a system of two interacting oscillators, the dynamical process can be presented as:

$$
\dot{\varphi}_{i}=\omega_{i}+q_{i}\left(\varphi_{i}, \varphi_{j}\right)+\xi_{i},
$$

where $\varphi_{i}$ is the phase of the $\mathrm{i}$-th oscillator, $\omega_{i}$ is its phase velocity, $q_{i}$ is the coupling function describing the interaction between the two oscillators and $\xi_{i}$ is the noise. The noise is assumed to be white, Gaussian, described as $\left\langle\xi_{i}(t) \xi_{j}(\tau)\right\rangle=\delta(t-\tau) E_{i j}$ and the information about the correlation between the noises of the two oscillators is included in the symmetric matrix $E_{i j}$.

Because of the periodic behavior of the system, it can be represented by Fourier decomposition. The dynamics will usually be well described by a finite number of Fourier terms and (1) can be written as:

$$
\dot{\varphi}_{i}=\sum_{k=-K}^{K} c_{k}^{i} \Phi_{i, k}\left(\varphi_{i}, \varphi_{j}\right)+\xi_{i}(t),
$$

where $i=1,2, \Phi_{1,0}=\Phi_{2,0}=1, c_{0}^{i}=\omega_{i}$, and the rest $\Phi_{i, k}$ and $c_{k}^{i}$ are the K-most important Fourier components.

Thus, the inference of the coupling functions describing the interaction between the oscillators will be reduced to inference of the unknown parameters of the model $M=\left\{c_{k}^{i}, E_{i j}\right\}$.

In the application of the dynamical Bayesian inference method, two time series of phases $\chi=$ $\left\{\varphi_{i, n} \equiv \varphi_{i}\left(t_{n}\right)\right\},\left(t_{n}=n h, i=1,2\right)$ are obtained from measurements and subsequent phase extraction procedure. The inference of the unknown parameters of the model is achieved by using the Bayes' theorem in order to maximize the conditional probability of observing parameters $M$, given the data $\chi$. Knowing the prior density $p_{\text {prior }}(M)$ of the parameters and the likelihood function $l(\chi \mid M)$, the Bayesian theorem provides a way to determine the posterior density of the unknown parameters, conditioned on the observation $M$ :

$$
p_{\chi}(M \mid \chi)=\frac{l(\chi \mid M) p_{\text {prior }}(M)}{\int l(\chi \mid M) p_{\text {prior }}(M) \mathrm{d} M} .
$$

Further theoretical details about the method are given in the literature [8], [6], [12], [23].

When applying the method in practice, certain initial assumptions about the unknown parameters are made and then the method is recursively applied. The time series of the phases are organized in subsequent blocks of samples. Each block includes 
certain amount of subsequent phases defined by the time duration of the block. The time duration of the block is called the time window $t_{w}$. For each block of data an inference is made and a set of values for the unknown parameters is obtained. The output set of values for the parameters from the previous block becomes the input for the following block of inference. In each following step of the inference, for each subsequent block of data, the inferred parameters are closer to their real values. With each step, along with the model parameters, the concentration matrix for the set of parameters is inferred as well. The concentration matrix is the inverse of the covariance matrix, which gives the variances of the inferred parameters.

Since the method infers dynamical systems in the presence of noise, the inferred set of parameters need to accurately follow the time evolution of the system and at the same time distinguish the noise from the dynamical effects. Therefore, in the propagation sequence of the method, the input covariance matrix for the following block is taken as a convolution of the covariance matrix of the current block and a diffusion matrix defined by the normal diffusion of each of the parameters: $\Sigma_{\text {prior }}^{n+1}=$ $\Sigma_{\text {post }}^{n}+\Sigma_{\text {diff }}([8,16])$. The diffusion matrix describes which part of the dynamical field defined by the oscillators is changed and the intensity of those changes. The elements of this matrix are given by $\left(\Sigma_{\text {diff }}\right)_{i, j}=\rho_{i j} \sigma_{i} \sigma_{j}$, where $\sigma_{i}$ is the standard deviation of the diffusion of parameter $c_{i}$, after time window $t_{w}$ from the previous to the next block of samples and $\rho_{i, j}$ describes the correlation between the changes of parameters $c_{i}$ and $c_{j}$. In the method, a special case is assumed when there is no correlation between the parameters $\rho_{i, j}=0$, for $i \neq j$ and every standard deviation $\sigma_{i}$ is a known fraction of the corresponding parameter $c_{i}: \sigma_{i}=\mathrm{p}_{w} c_{i}$, where $p_{w}$ is a constant parameter called propagation parameter. The index $w$ in $p_{w}$ emphasizes that the propagation parameter is determined for a time window of length $t_{w}$. The propagation parameter defines how much variability should be sought for in the inference. It balances between making an accurate inference of the time variability of the parameters and not involving too much random noise.

In the earlier applications of the method of dynamical Bayesian inference [8], [6], [24 - 26] the time window and the propagation parameter were arbitrarily selected, based on the experience of the investigator. Recently we proposed a method for adaptive determination of these parameters [20]. The method is based on analysis of systems of two coupled oscillators in the presence of noise. The coupled oscillators were represented by differential equation systems whose parameters were pre-selected and thus known in advance. From such differential equation systems we generated numerical signals for the phases of the oscillators. These generated phases were input data for the dynamical Bayesian inference. As output parameters, for each block of inference, we obtained the inferred model parameters and noises. These are actually the inferred model parameters and noises at specific time points of the evolution of the dynamical systems. Since we know the dynamical system in advance, we were able to compare the inferred parameters with their true values at specific time points.

As an output value, for each block of inference we obtained the concentration matrix $\Xi$ as well and from it we calculated the covariance matrix $\Sigma$ as an inverse of the concentration matrix $\left(\Sigma=\Xi^{-1}\right)$. The covariance matrix was used as an indicator of the quality of the inference. The element of the covariance matrix in the $(i, j)$ position is by definition the covariance between the $i$-th and $j$-th element of a multidimensional random vector. For $i=j$, the covariance of each element is obtained, which means that the matrix elements on the main diagonal of the covariance matrix are the variances of the variables. Since the standard deviation is the square of the variance, by minimizing the covariance matrix, we are minimizing the standard deviations of the inferred parameters. Therefore, we used the sum of the squares of all the elements of the covariance matrix $Q_{\Sigma}=\operatorname{Sum}_{i, j}\left(\Sigma_{i, j}^{2}\right)$ as an indicator of deviation of the inferred parameters from their real intrinsic values. Our simulations showed that the elements on the main diagonal of the covariance matrix are dominant, so it makes no difference whether we use the sum of the squares of all the elements in the matrix or just the sum of the squares of the elements along the main diagonal. We denote the sum of the squares of all the elements in the matrix as the quadrature covariance matrix.

In addition, we evaluated the differences between the inferred parameters $c_{i}$ and noises strengths $E_{i}$ and their true values $\widetilde{c_{l}}$ and $\widetilde{E_{l}}: \Delta c_{i}=c_{i}-\widetilde{c_{l}}$ and $\Delta E_{i}=E_{i}-\widetilde{E}_{l}$. We have introduced the procedure for the adaptive determination of the time window and the propagation parameter by analyzing a system of coupled phase oscillators in the presence of noise. We have then tested the procedure on a system of coupled limit-cycle oscillators in the presence of noise and in this paper we will present the details of this investigation. 


\section{RESULTS AND DISCUSSION}

The system of coupled limit-cycle oscillators that was investigated was comprised of two coupled
Poincarè oscillators in presence of white noise. The differential equations describing this system are given by (4):

$$
\begin{aligned}
& \dot{x}_{1}=-\left(\sqrt{x_{1}^{2}+y_{1}^{2}}-1\right) x_{1}-\omega_{1}(t) y_{1}+\varepsilon_{1}\left(x_{2}-x_{1}\right)+\xi_{1}(t) \\
& \dot{y}_{1}=-\left(\sqrt{x_{1}^{2}+y_{1}^{2}}-1\right) y_{1}+\omega_{1}(t) x_{1}+\varepsilon_{1}\left(y_{2}-y_{1}\right)+\xi_{2}(t) \\
& \dot{x}_{2}=-\left(\sqrt{x_{2}^{2}+y_{2}^{2}}-1\right) x_{2}-\omega_{2} y_{2}+\varepsilon_{2}(t)\left(x_{1}-x_{2}\right)+\xi_{3}(t) \\
& \dot{y}_{2}=-\left(\sqrt{x_{2}^{2}+y_{2}^{2}}-1\right) y_{2}+\omega_{2} x_{2}+\varepsilon_{2}(t)\left(y_{1}-y_{2}\right)+\xi_{4}(t)
\end{aligned}
$$

The periodic time-variability in this system was introduced in the frequency of the first oscillator,

$$
\omega_{1}(t)=1-0.4 \sin 2 \pi f_{1} t
$$

and in the coupling from the first to the second oscillator,

$$
\varepsilon_{2}(t)=0.2-0.1 \sin 2 \pi f_{2} t
$$

The noises were white and Gaussian, with no correlation between them. In the simulations, the strengths of the noises were varied in the interval $E_{i} \in[0.005,0.05], i=1,2,3,4$. The frequency of the second oscillator was $\omega_{2}=4.9$, while the coupling parameter from the second to the first oscillator was varied in the interval $\varepsilon_{1} \epsilon[0.005,005]$. The frequency of the time variability was changed in the interval $f_{i} \in[0.0015,0.02], i=1,2$.

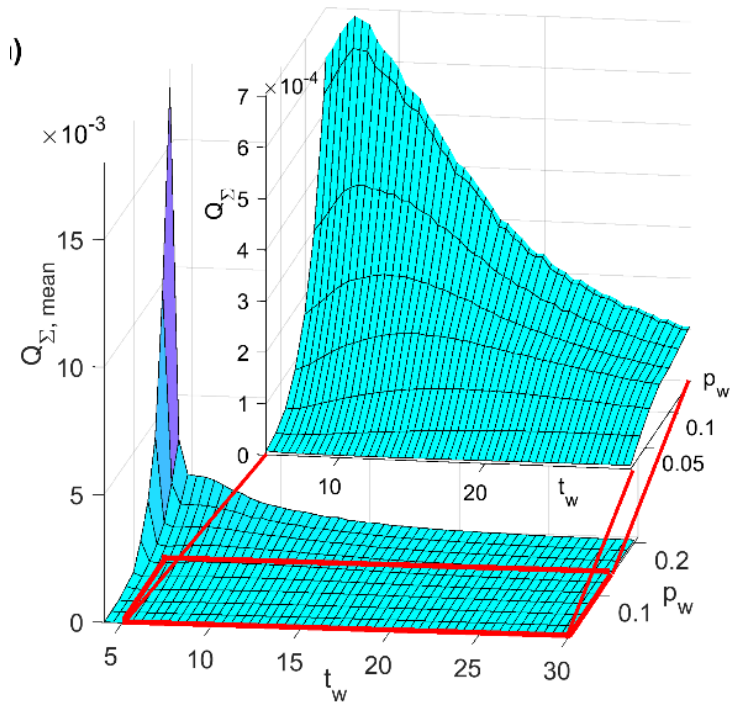

In Figure 1 we present a typical result of the simulations on how the quadrature covariance matrix $Q_{\Sigma}$ changes with the time window $t_{w}$ and the propagation parameter $p_{w}$. In Figure 1a we present the calculated average $Q_{\Sigma, \text { mean }}$ of all the blocks of the inference, excluding the first two blocks, while in Figure $1 \mathrm{~b}$ the $Q_{\Sigma}$ of the last inference block is given. When calculating the 3D graphs such as the one shown in Figure 1, all inferred values were averaged on between 5 and 50 trajectories in the phase space.

These results for the Poincarè oscillators confirmed the findings of the simulations for the phase oscillators that the dependence of $Q_{\Sigma}$ on the time window shows a maximum which is obtained for a value of the time window approximately reciprocal to the value used for the propagation parameter $t_{w, \max }=1 / p_{w}$ as shown in Figure 2. b)

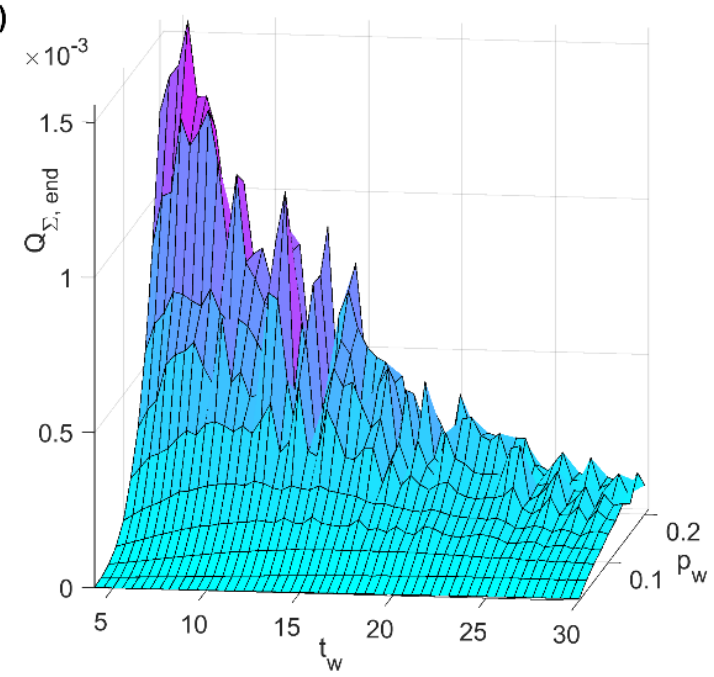

Fig. 1. Typical look of the dependance of the quadrature covarince matrix $Q_{\Sigma}$ on the time window $t_{\mathrm{w}}$ and the propagation parameter $\mathrm{p}_{\mathrm{w}}$. In a) the average quadrature covariance matrix $Q_{\Sigma \text {,mean }}$ of all the inference blocks, excluding the first two blocks is given and in b) the quadrature covariance matrix $Q_{\Sigma \text {,end }}$ for the last inference block is given 


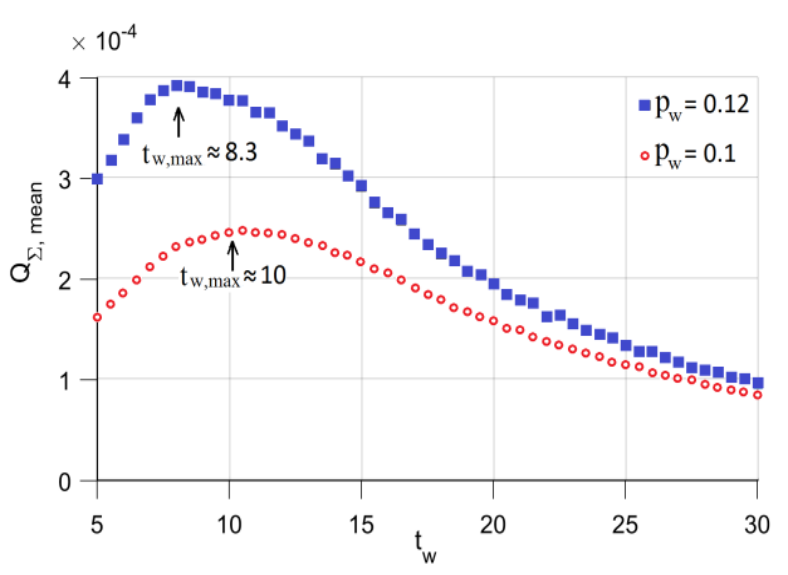

Fig. 2. $Q_{\Sigma \text {, mean }}$ as a function of $t_{w}$ for two different values of $p_{w}$. The maximum of the curve is obtained for values of the time window approximately given by $t_{w, \max }=1 / p_{w}$

The analysis also shows that the covariance matrix increases with increasing propagation parameter for a fixed time window, as can be seen in Figure 3. The $p_{w}$ dependence of $Q_{\Sigma}$ achieves saturation for very high values of $p_{w}$. Due to the large drop in $Q_{\Sigma}$ with increasing time window, the $Q_{\Sigma}$ axis is given in a logarithmic scale.

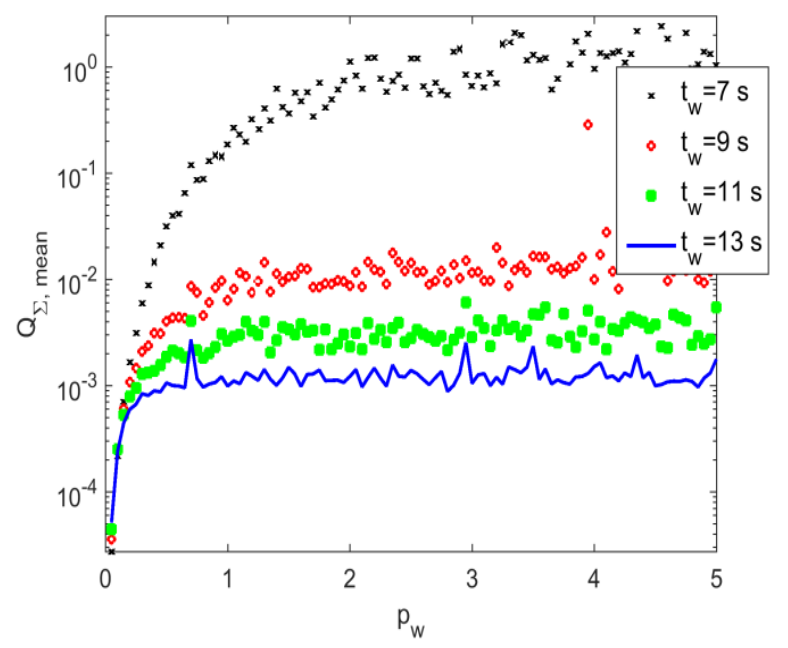

Fig. 3. $Q_{\Sigma, \text { mean }}$ as a function of $p_{w}$ for three different values of $t_{w}$. The curve reaches a plateu for high values of $p_{w}$

Similarly to the case of phase oscillators, for all values of $t_{w}$ and $p_{w}$ that put the inference to the left of the maximum of the curve $Q_{\Sigma}=Q_{\Sigma}\left(t_{w}, p_{w}=\right.$ const.) the inference enters the regime of delayed inference, where the inferred parameters do not reach the amplitude of change of the true values for the time varying parameters. The delayed inference regime obtained for the case of Poincarè oscillators is shown in Figure 4.

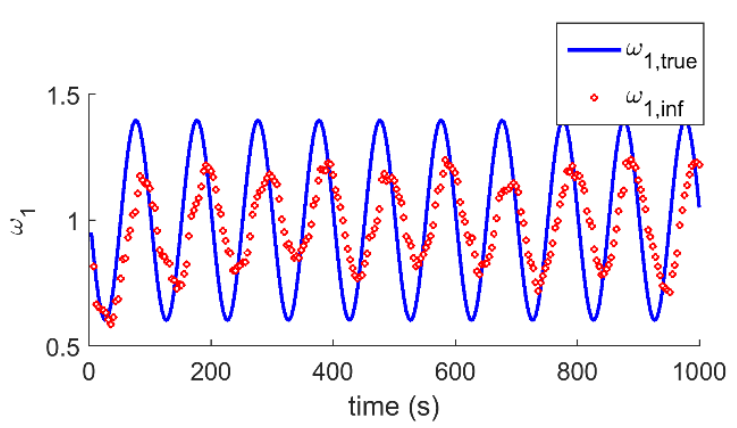

Fig. 4. Delayed inference regime - when the values of $t_{w}$ and $p_{w}$ are such that the inference is on the left of the maximum of the curve $Q_{\Sigma}=Q_{\Sigma}\left(t_{w}, p_{w}=\right.$ const. $)$, the inferred parameter (dotted line) does not reach the amplitude of change of its true value (solid line)

For values of $t_{w}>t_{w, \max }$, when $p_{w}=$ const., the covariance matrix decreases with increasing $t_{w}$. At the same time, the simulations show that the deviations of the inferred parameters from their true values also decrease.

The findings presented in Figures 1-4 confirm the findings of the investigation of phase oscillators, that in order to achieve the best quality of inference the investigator should use time window as big as possible. However, by increasing the time window, we reduce the possibility of describing the time-variability of the parameters. This is illustrated in Figure 5 where we present the influence of the time window (the width of the block of inference) on the description of the time variability.
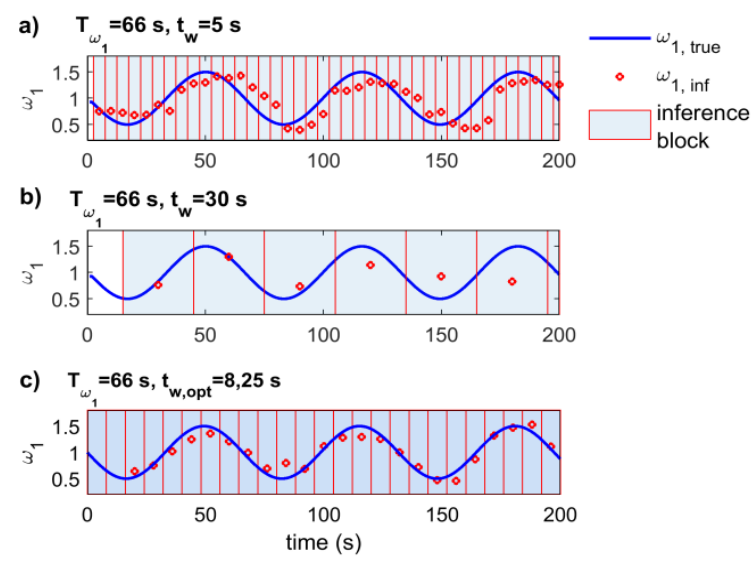

Fig. 5. Influence of the time window on the description of the time variability: a) narrow block of inference,

b) wide block of inference, c) optimal block of inference

In Figure 5a a narrow block of inference, i.e. small time window is presented, while in Fig.5b a wide block of inference is presented. It can be seen 
that when a narrow block of inference is used, more data points are inferred, hence the time variability is better described. If a wide block of inference is used, only few points would be obtained and the time-variability of the parameters would be missed. For this reason, in the algorithm proposed in [20] the optimal time window is chosen as one eight of the period of the fastest changing parameter. In this way there will be 8 data points ( 8 inference blocks) describing one full oscillation of the fastest changing parameter. For all the other time-varying parameters there will be more inferred points describing their time variability. This is shown in Figure 5c, where the optimal time window is used.

The frequency of the fastest changing parameter is obtained by performing an initial inference with a fixed, reasonably large, propagation parameter and a time window as small as possible [20]. In this way, the best possible inference of the time variability is achieved, at the expense of greater noise. For very small values of the time window the Matlab code for dynamical Bayesian inference will not work because the calculated concentration matrix will be too small and the code will give error mes-

a)
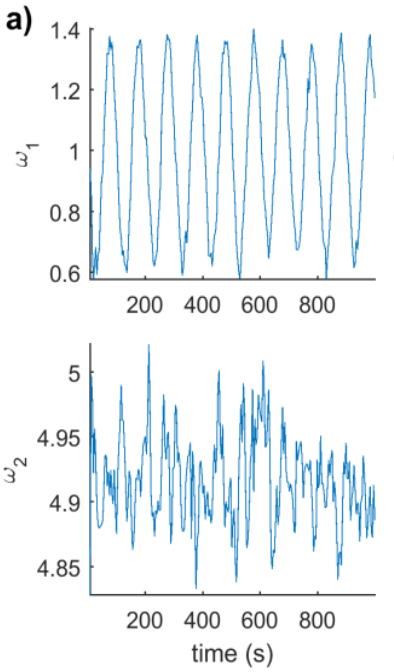
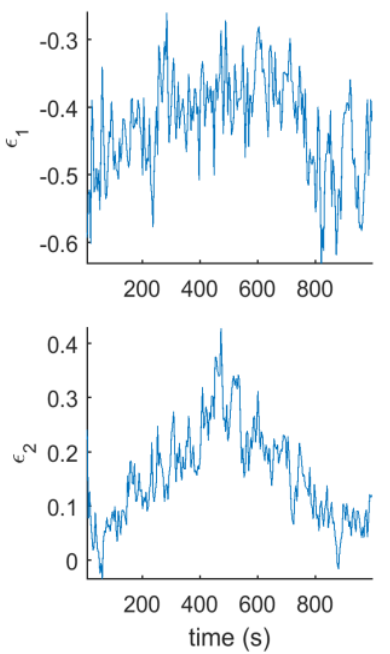

b)
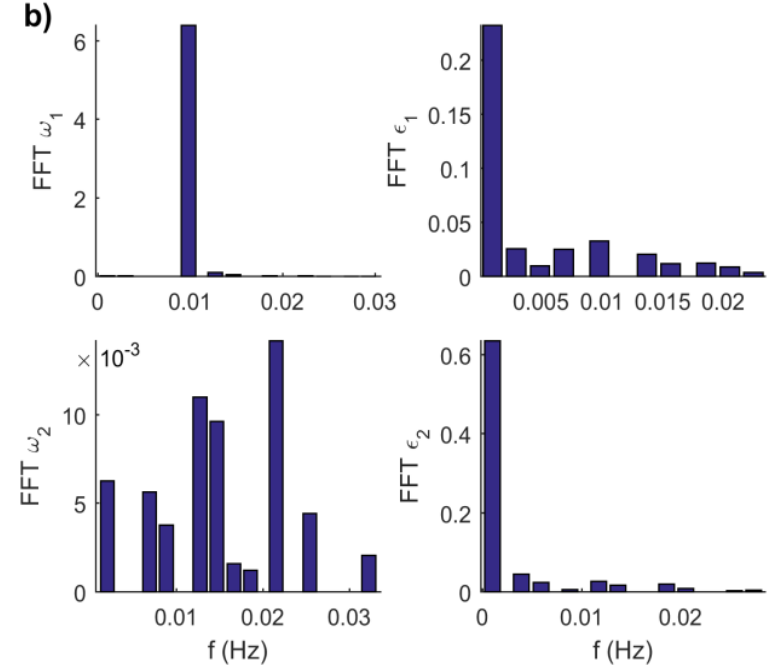

sage "Singular Matrix Error" for the calculated covariance matrix. This will define the lower limit of the time window that can be used. Once the initial inference of the parameters of the model and the noises strengths is performed, a fast Fourier transform of the parameters is performed. By analyzing the dynamics of the parameters and their fast Fourier transforms, the highest frequency $f_{\max }$ of parameter change is determined and from there, the corresponding period $T_{\min }=1 / f_{\max }$ is determined. The optimal time window is then taken as $t_{w, o p t}=T_{\mathrm{min}} / 8$.

For the case of coupled Poincarè oscillators that is under investigation, this is illustrated in Figure 6 . Since there are $2 \times 25$ base functions in the dynamical Bayesian inference method, there will be $2 \times 25$ parameters respectively. In Figure 6 only the four parameters of interest are shown. Figure $6 \mathrm{a}$ shows the inferred parameters from the initial inference, while Figure $6 \mathrm{~b}$ shows the fast Fourier transforms of the inferred parameters, respectively. In Figure 6 the maximal frequency of the time variability of the parameters is $f_{\max }=0.01 \mathrm{~Hz}$, so the inferred optimal time window would be

$$
t_{w, o p t}=T_{\min } / 8=1 / 8 f_{\max }=12.5 \mathrm{~s} .
$$

Fig. 6. Initital inference of the parameters of the system of coupled Poincarè oscillators. Only the four parameters of interest are shown: a) the inferred parameters, b) the fast Fourier transforms of the inferred parameters, respectively.

Once the time window is determined, according to Fig.3, the propagation parameter should be as small as possible. At the same time, the propagation parameter should be greater than $1 / t_{w, \text { opt }}$, in order not to enter the delayed inference regime. In order to test whether the proposed algorithm in [20] is valid for the case of coupled Poincarè oscillators, we investigated the difference between the inferred time varying parameters and their true values for different strengths of the noise and for different frequencies of the time varying parameters, corresponding to the frequency range of the cardiorespiratory interactions. We evaluated this difference by calculating the mean square error (MSE) between the time series of the inferred parameters with optimal time windows $t_{w, o p t}$ and their true values at the 
corresponding times. The first two blocks of the inference were again excluded. The MSE was calculated for different values of the propagation parameter and a graph $M S E=M S E\left(p_{w}\right)$ was constructed. In Figure 7 a typical example of the graph $M S E=$ $M S E\left(p_{w}\right)$ is shown. In parallel with the MSE investigation, we followed how the inferred parameters describe the time variability of their true values by following the graphs like the one presented in Figure 4.

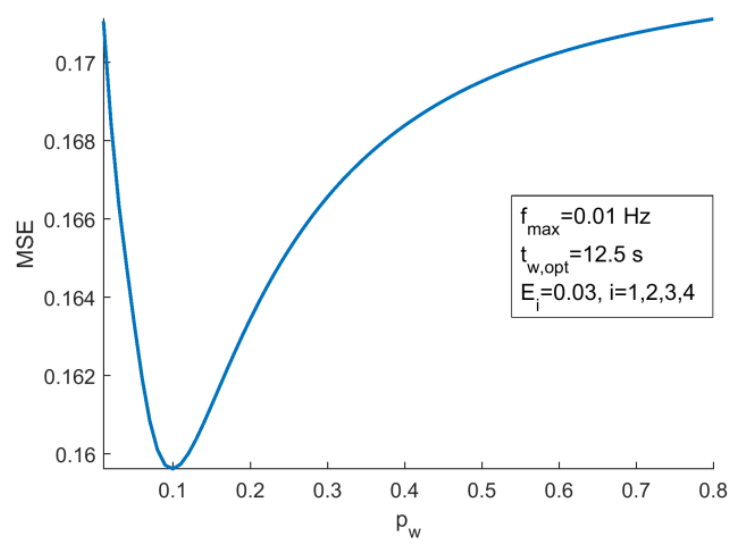

Fig. 7 Typical example of the dependance of the mean square error MSE between the four inferred parameters and their true value as a function of the propagation parameter $p_{w}$, for the optimal value of the time window $t_{w}$

From such investigations we confirmed that the optimal value of the propagation parameter depends both on the value of the optimal time window $t_{w, o p t}$ (i.e. on the frequency of the fastest changing time variable parameter $f_{\max }$ ) and on the strength of the noise $E_{i}$. For the noise strengths under investigation we confirmed that the optimal propagation parameter is approximately linearly dependent on $f_{\max }$. The slope and the intercept of the linear fit were found to depend on the inferred noise strengths represented by $E_{\text {sqrt }}=\sqrt{E_{11}^{2}+E_{22}^{2}}$, where $E_{i i}$ are the inferred noise strengths along the main diagonal. The dependence was found to be approximately described by inverse power law and the coefficients of the inverse power law were different from the case of coupled phase oscillators. However, the values obtained for $p_{w, o p t}$ in this way were always smaller than the ones obtained for the coupled phase oscillators, which is expected, since the case of the phase oscillators can be regarded as more general and encompassing the case of limit cycle oscillators. This is shown in Figure 8 (reprinted from [20]) and it means that the algorithm proposed in [20] will give satisfactory results, with a bit more noise included in the inference, compared to taking smaller values for $p_{w, o p t}$.

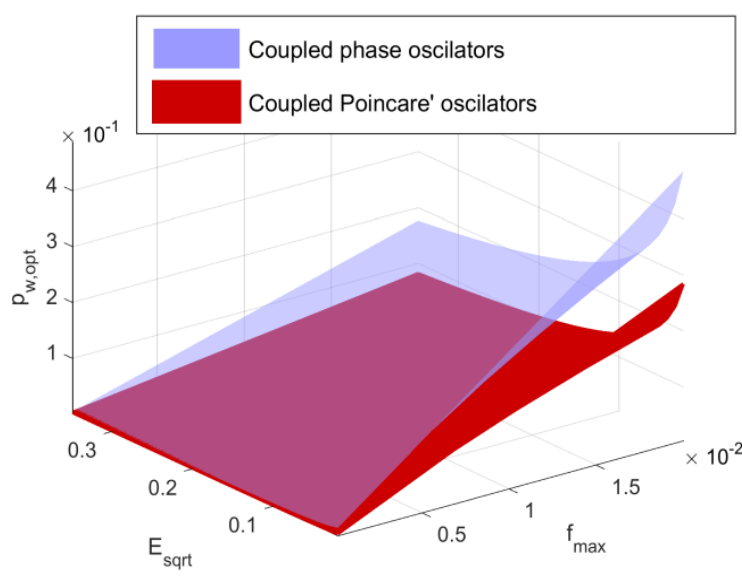

Fig. 8. Optimal propagation parameter as a function of the maximal frequency of parameter change and the noise, for the cases of coupled phase oscillators and coupled Poincarè oscillators (reprint from [20])

\section{CONCLUSION}

In this paper, we analyzed a system of Poincarè limit-cycle oscillators in order to check the proposed algorithm for determining the time window and the propagation parameter within the dynamic Baesian inference method. The analysis is aimed at establishing a protocol for adaptive dynamic Bayesian inference that will give a more accurate description of the model that describes a system of coupled oscillators in the presence of noise. The results confirm that the algorithm proposed in [20] will give an improved inference of the model that will describe the time variable system and thus allow more accurate examinations of the coupling functions that describe the interactions between different oscillatory systems in nature.

\section{REFERENCES}

[1] Stefanovska, A.: Coupled oscillators: complex but not complicated cardiovascular and brain interactions, IEEE Engineering in Medicine and Biology Magazine, Vol. 26, No. 6, 25-29 (2007).

[2] Schäfer, C., Rosenblum, M. G., Kurths, J., Abel, H. H.: Heartbeat synchronized with ventilation, Nature, Vol. 392, No. 6673, 239-240 (1998).

[3] Elstad, M., O’Callaghan, E. L., Smith, A. J., Ben-Tal, A., Ramchandra, R.: Cardiorespiratory interactions in humans and animals: rhythms for life, American Journal of 
Physiology-Heart and Circulatory Physiology, Vol. 315, No. 1, H6-H17 (2018).

[4] Buzsáki, G., Draguhn, A.: Neuronal oscillations in cortical networks, Science, Vol. 304, No. 5679, 1926-1929 (2004).

[5] Park, H. J., Friston, K.: Structural and functional brain networks: from connections to cognition, Science, Vol. 342, No. 6158, 1238411 (2013).

[6] Eckberg, D. L.: Topical review: The human respiratory gate, The Journal of Physiology, Vol. 548, No. 2, 339-352 (2003).

[7] Rosenblum, M. G., Pikovsky, A. S.: Detecting direction of coupling in interacting oscillators, Phys. Rev., Vol. 64, No. 4, 045202(R) (2001).

[8] Stankovski, T., Duggento, A., McClintock, P. V. E.,and Stefanovska, A.: Inference of time-evolving coupled dynamical systems in the presence of noise, Phys. Rev. Lett., Vol. 109, No. 2, 024101 (2012).

[9] Tokuda, I. T., Jain, S., Kiss, I. Z., Hudson J. L.: Inferring Phase Equations from multivariate time series, Phys. Rev. Lett., Vol. 99, No. 6, 064101 (2007).

[10] Schwabedal, J. T. C., Pikovsky, A.: Effective phase dynamics of noise-induced oscillations in excitable systems, Phys. Rev. E, Vol. 81, No. 4, 046218 (2010).

[11] Galán, R. F., Ermentrout, G. B., Urban, N. N.: Efficient Estimation of phase-besetting curves in real neurons and its significance for neural-network mModeling, Phys. Rev. Lett., Vol. 94, No. 15, 158101 (2005).

[12] Timme, M.: Revealing Network Connectivity from response dynamics, Phys. Rev. Lett., Vol. 98, No. 22, 224101 (2007).

[13] Stankovski, T., Cooke, W. H., Rudas, L., Stefanovska, A., Eckberg, D. L.: Time-frequency methods and voluntary ramped-frequency breathing: a powerful combination for exploration of human neurophysiological mechanisms, Journal of Applied Physiology, Vol. 115, No. 12, 18061821 (2013).

[14] Friston, K. J., Harrison, L., Penny, W.: Dynamic causal modelling, Neuroimage, Vol. 19, No. 4, 1273-1302 (2003).

[15] Kuramoto, Y.: Chemical Oscillations, Waves, and Turbulence, Berlin: Springer-Verlag (1984).

[16] Duggento, A., Stankovski, T., McClintock, P. V. E., Stefanovska, A.: Dynamical Bayesian inference of time-evolving interactions: from a pair of coupled oscillators to networks of oscillators, Phys. Rev. E, Vol. 86, No. 6 , 061126 (2012).

[17] Stankovski, T., Pereira, T., McClintock, P. V. E., Stefanovska, A.: Coupling functions: universal insights into dynamical interaction mechanisms, Rev. Mod. Phys., Vol. 89, No. 4, 045001 (2017).

[18] Stankovski, T., Pereira, T., McClintock, P. V. E., Stefanovska, A.: Coupling functions: dynamical interaction mechanisms in the physical, biological and social sciences, Phil. Trans. R. Soc. A, Vol. 377, No. 2160, 20190039 (2019).

[19] Stankovski, T., Ticcinelli, V., McClintock, P. V., Stefanovska, A.: Neural cross-frequency coupling functions, Frontiers in systems neuroscience, Vol. 11, No. 33 (2017).

[20] Lukarski, D., Ginovska, M., Spasevska, H., Stankovski, T.: Time window determination for inference of time-varying dynamics: application to cardiorespiratory interaction, Front. Physiol., Vol. 11, 341, (2020)

[21] Nakao, H., Yanagita, T., Kawamura, Y.: Phase-reduction approach to synchronization of spatiotemporal rhythms in reaction-diffusion systems, Phys. Rev. X, Vol. 4, No. 2, 021032 (2014).

[22] Smelyanskiy, V. N., Luchinsky, D. G., Stefanovska, A., McClintock, P. V. E.: Inference of a nonlinear stochastic model of the cardiorespiratory interaction, Phys. Rev. Lett., Vol. 94, No. 9, 098101 (2005).

[23] Bayes, T.: Phil. Trans. R. Soc. London, Vol. 53, No. 370, (1763).

[24] Iatsenko, D., Bernjak, A., Stankovski, T., Shiogai, Y., Owen-Lynch, P. J., Clarkson, P. B. M., McClintock, P. V. E., Stefanovska, A.: Evolution of cardiorespiratory interactions with age, Phil. Trans. R. Soc. A, Vol. 371, No. 1997, 20110622 (2013).

[25] Stankovski, T., Petkoski, S., Raeder, J., Smith, A. F., McClintock, P. V. E., Stefanovska, A.: Alterations in the coupling functions between cortical and cardio-respiratory oscillations due to anaesthesia with propofol and sevoflurane, Phil. Trans. R. Soc. A Vol. 374, No. 2067, 20150186 (2016)

[26] Ticcinelli, V., Stankovski, T., Iatsenko, D., Bernjak, A., Bradbury, A. E., Gallagher, A. E., Clarkson, P. B. M., McClintock, P. V. E., Stefanovska, A.: Coherence and coupling eunctions reveal microvascular impairment in treated hypertension, Front. Physiol., Vol. 8, 749 (2017). 